\title{
La variación de los precios del petróleo y su influencia en las economías de Colombia y Ecuador. Análisis comparativo de indicadores macroeconómicos y sociodemográficos entre 2008 y 2017
}

\author{
The variation in oil prices and their influence in the economies of Colombia \\ and Ecuador. Analysis comparison of macroeconomic indicators and \\ sociodemographic between 2008 and 2017
}

Recibido: 20-03-2019 • Aprobado: 24-05-2019 • Página inicial: 185 - Página final: 207

\author{
César Augusto García Marín*
}

\begin{abstract}
Resumen: este artículo analiza la relación que existe entre la fl uctuación de los precios del petróleo y varios indicadores de percepción económica en Colombia y Ecuador entre los años 2008-2017. Para lo cual se tomó información secundaria correspondiente al comportamiento del precio del petróleo de referencias WTI y BRENT, junto a datos macroeconómicos de ambas naciones y las encuestas de Latinobarómetro en cada año objeto de estudio, para conocer la percepción de los ciudadanos sobre la economía de sus países. Esta información fue analizada a través de dos modelos estadísticos. Primeramente, tomando el precio del petróleo y ver si las variables macroeconómicas escogidas son independientes de la fl uctuación de este; por último, a través de una regresión de Poisson, se analizó si hubo o no relación entre la percepción económica y la variación del precio del petróleo. Con dicha información hemos encontrado una divergencia entre el pensar de la población sobre la economía y las afectaciones que pueda tener la variación positiva o negativa del precio internacional del petróleo.
\end{abstract}

Palabras clave: crecimiento Económico, Economía, Precio del Petróleo, Percepción, WTI, BRENT, PIB.

\begin{abstract}
This article analyzes the relationship between the variation of international oil prices and its effects on indicators of economic perception in Colombia and Ecuador from 2008 to 2017. To achieve this, we used secondary sources regarding the oil price average -considering just WTI and BRENT referencesfor each year, and other macroeconomic indicators. This information was analyzed through statistical models. First, we took Oil price as the main variable and we confronted each of the macroeconomic indicators collected to test whether they were independent from this main variable or not; second, we applied a Poisson regression to find if the citizen perception of the economy in these countries has a correlation with the booms and busts of oil prices. In the end, we found a divergence between the citizens' perception and the economy's positive or negative economic performance.
\end{abstract}

Keywords: Economic Growth, Economy, Oil Price, Perception, WTI, BRENT, GDP.

JEL: Q32

\footnotetext{
* Estudiante de noveno semestre del programa Administración Financiera e integrante del Semillero en Geopolítica de la Facultad de Ciencias Administrativas y Económicas del Tecnológico de Antioquia, Colombia. cesaragm2010@gmail.com ORCID: https://orcid.org/0000-0002-4197-0287
} 


\section{Contexto Garcia, c.}

\section{A variação dos preços do petróleo e sua influência nas economias da Colômbia e Equador. Análise comparação de indicadores macroeconômicos e sociodemográfico entre 2008 e 2017}

Resumo: este artigo analisa a relação que existe entre a flutuação dos preços de óleo e vários indicadores de percepção econômico na Colômbia e Equador entre Os anos de 2008-2017. Para o qual foi levado informação secundária correspondente a comportamento do preço do petróleo de Referências WTI e BRENT, junto com dados macroeconômico de ambas as nações e Pesquisas do Latinobarômetro em cada ano objeto de estudo, conhecer a percepção dos cidadãos sobre a economia de seus países Esta informação foi analisada através de de dois modelos estatísticos. Primeiro levando o preço do petróleo e ver se o variáveis macroeconômicas escolhidas são independente dessa flutuação; por por último, através de uma regressão de Poisson, foi analisado se havia ou não uma relação entre percepção econômica e variação de preços de óleo Com esta informação, temos encontraram uma divergência entre pensar no população sobre a economia e os efeitos que pode ter variação positiva ou negativa do preço internacional do petróleo.

Palavras-chave: crescimento econômico, Economia, Preço do Petróleo, Percepção, WTI, BRENT, PIB. 


\section{Introducción}

La volatilidad del precio internacional del petróleo es un factor de riesgo muy grande para los países exportadores de esta materia prima (commodity), máxime si estos son altamente petro-dependientes, es decir que sus economías tienen un alto grado de dependencia en la renta petrolera. Los casos de estudio en este trabajo, Colombia y Ecuador, son un ejemplo de cuánto daño puede ocasionar un descenso en el precio internacional del crudo WTI o Brent, sobre todo para las finanzas públicas. En este sentido, y como se podrá observar con los datos que hemos recopilado, una caída del precio genera grandes variaciones en el ingreso del gobierno nacional central, un menor recaudo por impuesto de rentas, menor transferencia en regalías y una caída en la producción o exploración. En Colombia, por ejemplo, según una investigación del Banco de la República (2016, p.8),

Con el aumento de la producción y de los precios, la participación del petróleo y sus derivados en las exportaciones totales del país creció gradualmente hasta alcanzar el $50 \%$ en 2011 y el $55 \%$ en 2013 . Con la caída del precio internacional esta participación descendió a 40\% en 2015.

Por otro lado, en Ecuador la renta del petróleo con respecto al PIB tuvo su momento más álgido en el 2008, cuando representó el 17,135\% y su momento más bajo en el 2015, cuando fue un 3,31\% (Banco Mundial, 2018).

Es decir, el impacto del precio del barril de petróleo no se percibe solamente en términos de ingresos fiscales o participación en el PIB, sino que también se ve reflejado en la balanza de pagos, a través de la cuenta corriente. Como la fluctuación en los precios del petróleo en países exportadores del mismo tiene un impacto tangible en la economía, cobra relevancia conocer la forma en que la población percibe estas variaciones y su posición al respecto. Por tal motivo, el interés principal de este artículo es hallar si existe alguna correlación entre los años de bonanza y crisis en las rentas petroleras y la percepción que la población tiene sobre la economía de sus naciones.

Para poder llevar a cabo esta investigación, hemos acudido a la recopilación de información de carácter económica, social y demográfica, política y de percepción, para así poder conocer con información secundaria: qué población había en cada año (las estimaciones anuales) en Colombia y Ecuador; cuál fue el crecimiento del PIB y del PIB per cápita; si se hicieron o no reformas tributarias en cada año y, finalmente, a través de las encuestas de percepción y opinión de Latinobarómetro, conocer qué idea tiene la gente sobre la economía de su país. 


\section{Contexto garca, c}

Por último, el cuerpo de este trabajo está dividido en varias sesiones, inicia con los antecedentes del problema, donde se recopila información sobre el precio del petróleo, el acontecer desde la crisis del 2008 en Ecuador y Colombia, y cuáles fueron las consecuencias de las subidas o bajadas del precio internacional del barril de petróleo, entre otras; esto se complementa con la revisión literaria donde se muestran estudios que han evaluado aspectos relacionados con el que trata este artículo, tanto en lo económico como en estudios sobre la percepción. Luego se detalla la metodología y los instrumentos usados para la investigación y el análisis de los datos, para terminar con el análisis y la discusión de los resultados y entregar las conclusiones.

\section{Objetivos}

General: Analizar la relación que existe entre la fluctuación de los precios del petróleo y varios indicadores de percepción económica en Colombia y Ecuador entre los años 2008-2017.

\section{Específicos:}

- Conocer la percepción que tiene la población sobre la situación económica del país.

- Estudiar y comparar el efecto que tiene la variación de los precios del petróleo sobre el bienestar económico percibido por la población de ambos países.

\section{Antecedentes del problema}

Los commodities son volátiles, se encuentran listados en las distintas bolsas mercantiles del mundo y desde allí se definen sus precios. El petróleo, como la principal entre todas las materias primas, no es la excepción a esta regla del mercado que, al menos desde la teoría básica, plantea un juego de libre oferta y demanda para establecer un valor a pagar por este bien. Pero no siempre es así, pues el petróleo, por su relevancia e importancia comercial, es objeto de distintas manipulaciones que permiten especular con su precio, dependiendo del lado de la balanza en que se encuentre; es decir, si se es comprador, vendedor o inversionista. Dichas intervenciones sobre el precio del petróleo pasan del plano económico al político, geoestratégico y militar. Así, distintos eventos geopolíticos y económicos tuvieron un fuerte impacto en el mercado del petróleo por más de 40 años (Sehgal y Pandey, 2015, p.235), antes de la Crisis Financiera Global del 2008: Guerras, tensiones entre estados (principalmente productores), sanciones o crisis económicas que afectaron hacia el alza o la baja el precio del petróleo. 
En los meses anteriores a la crisis, el petróleo alcanzó su valor máximo de USD 145 por barril y luego cayó, a finales del 2008, a USD 43 por barril (Sehgal y Pandey, 2015, p.235). La crisis estalló, y los principales consumidores de petróleo redujeron su consumo, lo que llevó a una sobreoferta y eventualmente a la caída del precio del barril de crudo. Luego vino un nuevo periodo de bonanza motivado por factores no económicos, como los conflictos en Medio Oriente, la Primavera Árabe, o las sanciones económicas de EE. UU. sobre Irán. Pero como en otras ocasiones, no duró para siempre.

Estados Unidos empezó a explotar e inundar los mercados con petróleo no convencional, mientras el resto de productores seguían produciendo y produciendo petróleo, hasta que de nuevo hubo sobreoferta, China dejó de demandar tanto crudo y la Unión Europea seguía en gran medida en recesión, y así los precios cayeron de nuevo en el 2014.

Hoy en día la tendencia es nuevamente alcista, pero persiste la incertidumbre; la especulación y los factores de riesgo continúan presionando el precio del barril hacia arriba y hacia abajo. Como es natural, esto afecta tanto a Colombia como a Ecuador, puesto que ambos países obtienen la mayor parte de sus ingresos de la renta petrolera; en el caso colombiano, como porcentaje del PIB, en su momento más relevante fue el 6,426\%, mientras en el PIB ecuatoriano representó el 17,135\% (Banco Mundial, 2018).

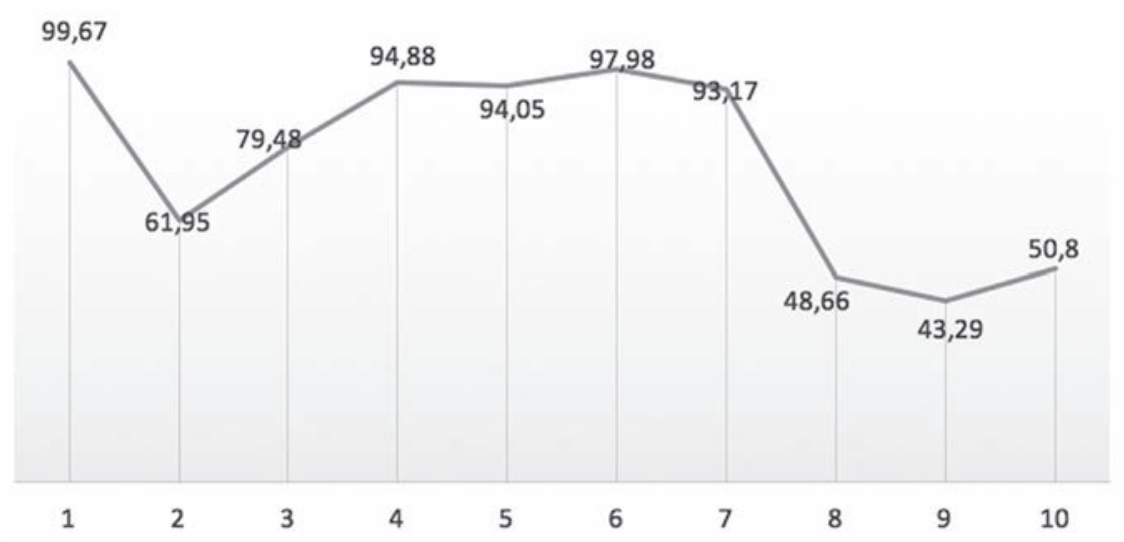

Figura 1. Precio petróleo WTI referencia para Ecuador.

Elaboración propia con base en Banco Mundial (2018). 


\section{Contexto Garcia, c.}

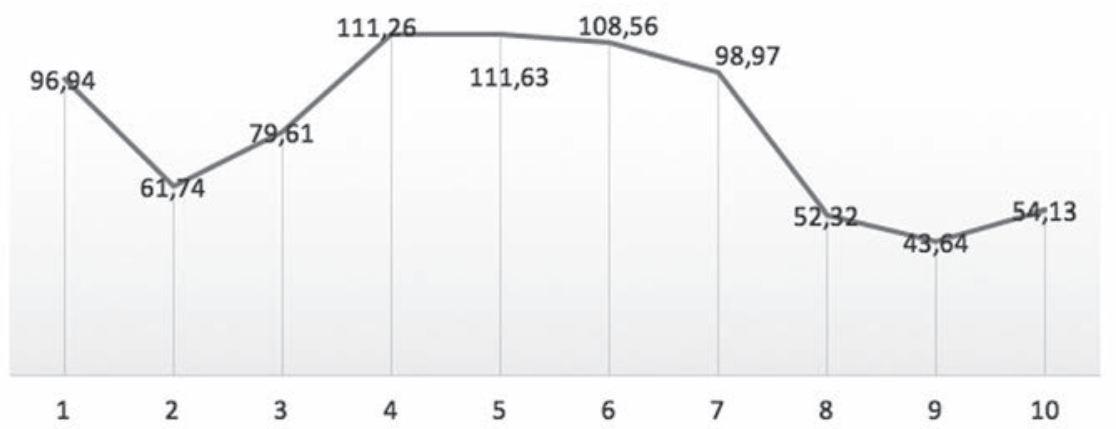

Figura 2. Precio petróleo BRENT referencia para Colombia.

Elaboración propia con base en Banco Mundial (2018).

\section{Revisión de literatura}

\section{El petróleo después de la crisis del 2008}

América Latina ha sido, a lo largo de su historia desde la conquista española, un importante centro de acopio de materias primas para el mundo entero. Oro, plata, café, caucho, etc., dieron a la región grandes bonanzas que ayudaron a cimentar el desarrollo de distintas ciudades; cada producto hizo su aporte en distintos periodos, pero el resultado siempre fue que luego de una gran riqueza generada por altos precios en el mercado internacional, vinieron fuertes desplomes de los precios, en ocasiones producto de una sobreoferta y, en otras, por una caída en la demanda. El petróleo, cuya relevancia no es generalizada en toda la región, por cuanto no todos los países son exportadores netos o grandes productores de esta materia prima, es hoy día el gran sustento de las economías de varios países de la región, principalmente de Venezuela, que cuenta con las reservas probadas más grandes del mundo, y además, Brasil, México, Colombia, Ecuador y Argentina.

Desde la crisis del 2008 hasta el 2014, el precio del barril de crudo ha pasado por distintos momentos que han marcado este periodo como una era de gran volatilidad. Dichos sucesos se pueden resumir así: la crisis financiera global que afectó principalmente a EE. UU. y otros países industrializados, que terminaron reduciendo la demanda; la crisis de la deuda soberana (2009-2012) en varios países europeos (España, Grecia, Portugal, Irlanda, Italia); la Primavera Árabe (2011), que afectó a grandes productores como Libia, y problemas políticos en Venezuela (que aún persisten), ambos sucesos presionaron el precio del barril al alza al reducirse la oferta; la explotación de petróleo no convencional en EE. UU., y, por último, la ralentización de la economía china, estos dos eventos una vez mellaron el precio del crudo y ejercer presión sobre este commodity, 
arrastrando el precio. El petróleo continúa siendo una variable económica de gran importancia que, frecuentemente viciada por eventos geopolíticos y por los ciclos económicos globales, representa una fuente crónica de incertidumbre para los productores y consumidores (Santillán y Venegas, 2015, p.1).

En general, los países dependientes de las exportaciones de petróleo en la región salieron bien librados de los acontecimientos acaecidos durante esta época turbulenta y volátil, puesto que pudieron continuar el ritmo de crecimiento, aunque con menor intensidad. Por ejemplo, en el caso de Colombia, que si bien no es considerada una nación petrolera como lo es Ecuador, el ingreso que percibe sí es muy relevante para las finanzas públicas de la nación e incluso como porcentaje de su PIB, tal como se aprecia en la Figura 2, o para la estabilización de su balanza comercial. Ecuador, por su parte, sí muestra una dependencia mucho más fuerte que Colombia en este sentido (ver Figura 1). En el período objeto de estudio, los gobiernos de ambos países tuvieron que sopesar los altibajos del petróleo para hacer frente a las necesidades de financiamientos que sus programas de gobierno demandaban. Así, en Colombia se pudo encontrar que hubo alrededor de cinco reformas tributarias en el período 2008-2017, mientras en Ecuador se crearon ocho leyes, en el mismo periodo, para modificar el sistema tributario y de esta forma poder obtener mayores ingresos a través de los impuestos.

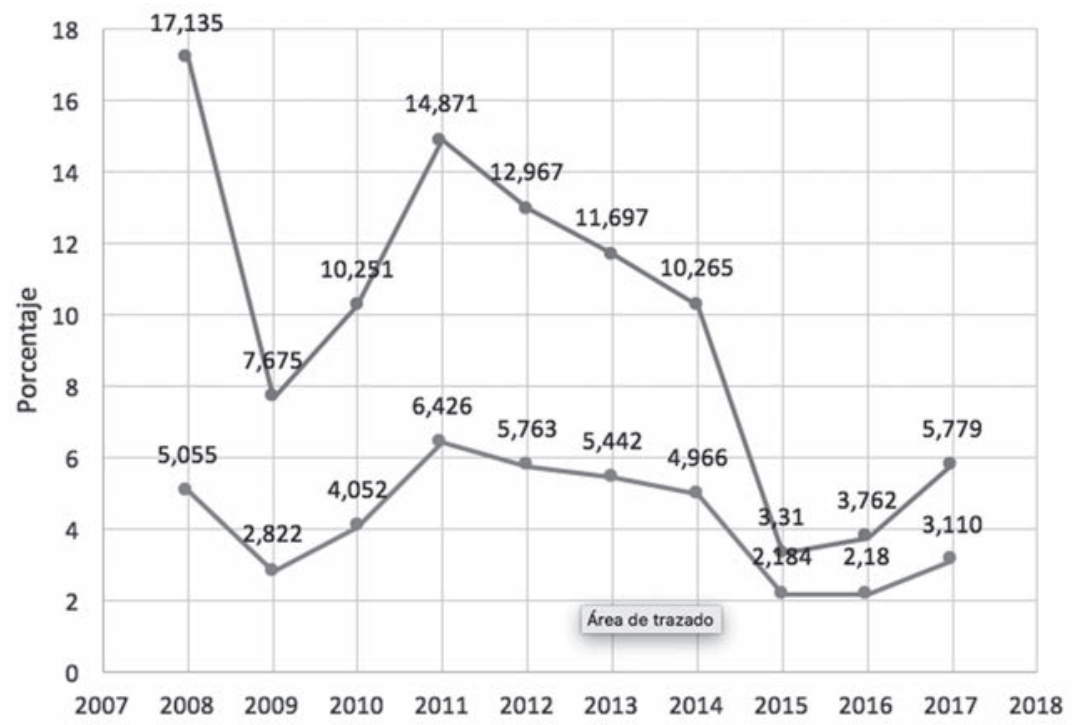

Figura 3. Comparativo del ingreso petrolero como porcentaje del PIB Colombia -Ecuador Elaboración propia con base en Banco Mundial (2018). 


\section{Contexto garca, c}

\section{Percepción e indicadores económicos}

Los estudios sobre la percepción son cada vez más comunes y han dado paso al desarrollo de la economía del comportamiento. Richard Thaler y Cass Sunstein (2008) argumentan que las personas no somos tan racionales como lo sugiere la teoría económica tradicional, sino que nos afectan ciertas falacias y sesgos al momento de tomar nuestras decisiones. En este sentido, resaltan la existencia permanente de varias heurísticas que modifican nuestra percepción y, en última instancia, el proceso de toma de decisiones.

La percepción económica ha sido utilizada comúnmente como un indicador para relacionar o tratar de predecir la dirección del voto de una determinada población. Por ejemplo, si la gente percibe que la economía va bien, probablemente se incline por volver a votar por un candidato que esté haciendo campaña por la reelección, mientras que si su percepción de la economía es negativa se inclinará por "castigar al candidato" y elegir a otro.

De hecho, la gran mayoría de los estudios relacionados con el "voto económico" se basan en la idea según la cual la percepción de la economía, y no las preferencias individuales de políticas públicas, es la fuerza principal que decide en elecciones nacionales. Kramer (1971), uno de los primeros en hacer este tipo de aseveración, ha visto confirmada su teoría gracias a estudios realizados en varias docenas de países (Lewis-Beck y Stegmaier, 2007; 2009). En Estados Unidos, el indicador principal que afecta la decisión de voto en la población es el PIB per cápita. Asimismo, los estudios realizados en América Latina confirman que los gobiernos son "castigados" o "gratificados" por la población en las elecciones dependiendo de su percepción del desempeño económico (Lewis-Beck y Ratto, 2013).

En un sentido más amplio, la percepción sobre la economía puede estar condicionada por variables reales (i. e. indicadores económicos). Sin embargo, ésta también puede verse influenciada por otros factores. De hecho, información muy valiosa sobre una determinada población viene dada por las brechas que existen entre el conocimiento real y la percepción. Una explicación para ello es la existencia de información imperfecta, que puede venir dada por el alto grado de confiabilidad que se otorga a las experiencias anecdóticas y a la información proveniente de los medios masivos de comunicación.

De esta forma, es muy común encontrar resultados en diversas investigaciones en los que se establece que existen varias paradojas con respecto al comportamiento 
de los indicadores económicos y la percepción que la población tiene al respecto. La paradoja del "campesino feliz y el triunfador frustrado" refleja que las personas más pobres no son aquellas que mencionan estar infelices o frustradas con el desempeño de la economía (Graham y Pettinato, 2002). Son varias explicaciones para este fenómeno, una de ellas establece que las personas pobres tienen menores expectativas y por lo tanto reportan mayores niveles de conformidad, mientras que otras explicaciones sostienen que tal vez dicha población tiene "niveles más altos de felicidad". Otra paradoja que se evidencia en la literatura es la paradoja del crecimiento, en ella se discute que si bien las personas reportan mayores niveles de felicidad conforme aumenta su PIB per cápita, cuando se controla este indicador y se trata de hallar la relación tomando en cuenta los niveles de crecimiento del país, las personas reportan menores niveles de felicidad.

Como se puede ver, la percepción de la economía se determina por varios factores, los cuales se pueden alinear a cuestiones más reales y a factores que vienen determinados por la influencia de los medios de comunicación, la existencia de heurísticas y, más ampliamente, por la información imperfecta.

\section{El petróleo, la economía y la percepción ciudadana}

El petróleo es el motor de la economía global por cuanto es la principal fuente de energía en el mundo, y al ser la base para el desarrollo de cualquier nación es imperativo que todas las personas tengan conocimiento, estén al tanto o al menos pendientes de lo que pueda ocurrir con los precios internacionales de este commodity sin importar si se habita en un país productor o no, ya que incluso los países importadores, al igual que los países productores de petróleo, se ven afectados por su volatilidad, aunque de forma inversa: un aumento en los precios es benéfico para el productor, pero no para el consumidor, y una disminución del precio tendría el efecto contrario.

La volatilidad de los precios puede tener distintos efectos en una economía, que estarán condicionados por la composición del PIB nacional, las condiciones políticas y el nivel de desarrollo de cada Estado. En el caso latinoamericano, por ejemplo, la disparidad entre los niveles de producción y reserva en cada uno de los países exportadores de petróleo genera diferencias en el impacto económico ante los cambios en los precios; adicionalmente, las diferencias en las políticas de cada país con respecto a la configuración del sector de hidrocarburos, generan distintos impactos o efectos cuando los precios suben o bajan. 


\section{Contexto Garcia, c.}

(...) las políticas de liberalización del sector o las que buscan su estatización han sido muy diferenciadas y se pueden apreciar distintos bloques. El primero fue México, en 1938, que a través de PEMEX, nacionalizó la industria; en los 90 del siglo pasado, Argentina, Venezuela, Bolivia y Ecuador buscaron la liberalización del sector, pero en la última década y media, cambiaron su postura -acorde a su modelo político-y aumentaron el control del Estado sobre esta industria. En contraparte, Brasil, Perú y Colombia, en distintos años, aumentaron la liberalización y estímulo al capital privado, aunque con la creación de entidades estatales encargadas de la regularización, y con la participación, en los casos de Colombia y Brasil, de sus empresas estatales de petróleo -Ecopetrol y Petrobras, respectivamente-. Sin embargo, dice el informe, entre 2003 y 2008, la tendencia fue la de una mayor participación del Estado, alentado por los altos precios previos a la Crisis Financiera Internacional. Aunque es de aclarar, que todos lo hicieron de forma distinta y siguiendo el modelo económico y político de los gobernantes de turno. Así, algunos países renegociaron los contratos de explotación, mientras otros aumentaron la participación del sector privado (CEPAL, 2013, p.35).

Por otro lado, también se resalta cómo América Latina ha disminuido su participación en el suministro global de petróleo, pero aun así no ha descendido en la cantidad de reservas que se estima hay en la región (CEPAL, 2013, p.36). Estos cambios tal vez podrían pasar o no desapercibidos para una parte de la población, aunque, en términos generales, hechos como estos que puedan afectar la economía deberían ser muy importantes en el diario vivir de una nación.

Según estudios, la población mayoritariamente pareciera tener un gran interés por el desarrollo económico, por citar un ejemplo, en medio de una elección. Los votantes son capaces de evaluar el desarrollo de un gobierno con respecto a todo su desempeño al mando del país, no solamente se interesan por los resultados económicos cercanos a las elecciones (Clegg, 2016). Esto con respecto al electorado británico. Es decir, hay casos en los que la economía es el principal incentivo para votar o no por un candidato/partido.

Por otro lado, otros estudios indican que la percepción de la economía es algo no del todo realista y que puede responder a otros factores. Tal es el caso de un estudio presentado por el Pew Research Centre (DeSilver, 2017), donde se aprecia que la forma de percibir el desarrollo económico de un país parece estar ligada a condiciones sociopolíticas propias de cada nación. El estudio realizó una serie de encuestas en 38 países del mundo para conocer la percepción de 
los ciudadanos con respecto a la economía de sus países. Así, por ejemplo, comparando los resultados de Grecia y Sudáfrica, ambos con tasas de desempleo muy similares ( $23,9 \%$ y $25,9 \%$, respectivamente), un $45 \%$ de los sudafricanos dijeron que la economía de su país estaba bien, contra un $2 \%$ de los griegos.

Según el estudio, no todos los casos fueron tan discrepantes en los resultados frente a la realidad; por ejemplo en Vietnam, que presentó entre los años 2011 y 2016 un incremento en el ingreso per cápita del 26,2\%, un $91 \%$ de sus ciudadanos consideraron las condiciones económicas actuales como buenas; situación similar ocurrió en India, donde gracias a un incremento del ingreso per cápita del $29,1 \%$, el $83 \%$ de la población encuestada consideró que las condiciones económicas del país eran buenas. Pero como se mencionó al inicio, hubo varias discrepancias, como en Venezuela, donde a pesar de una caída del $26,2 \%$ del ingreso per cápita, un $20 \%$ de la población consideró que las condiciones económicas del país eran buenas; en Corea del Sur en los años del estudio hubo un incremento del 12\% del ingreso per cápita, sin embargo, sólo el 15\% de los encuestados encontraron que la economía de su país era buena.

Hasta el momento hay estudios que indican que la percepción económica puede o no tener un papel preponderante en el sentir de una población. ¿De qué dependerá que la gente perciba que la condición económica es buena o mala? No hay un criterio único y parece que todo depende de las condiciones propias de cada país.

\section{Colombia y Ecuador: una relación difícil con el petróleo}

A pesar de tratar de diversificar su actividad económica, Ecuador es un país que aún es altamente dependiente del petróleo. De acuerdo con Karl (1997), las experiencias históricas han evidenciado que los países que se han especializado en la extracción y la exportación de recursos naturales no han logrado desarrollarse. La evidencia empírica sugiere que aquellos que disponen de una sustancial dotación de uno o unos pocos productos primarios parecen estar condenados al subdesarrollo, atrapados en "la paradoja de la abundancia". Varios estudios empíricos llevados a cabo con el fin de determinar el impacto de los precios del petróleo en el desarrollo económico han mostrado resultados mixtos: De Miguel, Manzano y Martín Moreno (2012) analizaron el impacto de la fluctuación de los precios del petróleo en la actividad económica en España $y$, mediante el empleo de un modelo econométrico VAR, lograron demostrar un efecto negativo del precio del petróleo en el crecimiento económico. 


\section{Contexto Garcia, c.}

Por otro lado, investigaciones dirigidas por Cuñado y Pérez de Gracia (2003) concluyeron que no hay una relación de cointegración a largo plazo entre la fluctuación de los precios del petróleo y la actividad económica, excepto para el Reino Unido e Irlanda. Por lo tanto, estos investigadores sugieren que la relación directa entre las dos variables se limita a observarse en el corto plazo. En el caso de China, la investigación conducida por Limin et al. (2010) sugiere que los indicadores macroeconómicos, como crecimiento e inflación, sí están afectados por la fluctuación de los precios del petróleo.

Ftiti, Guesmi y Teulon (2014) analizaron cuatro países productores de petróleo de la OPEP (EAU, Kuwait, Arabia Saudí y Venezuela), y encontraron que los países exportadores de petróleo son más sensibles a los cambios bruscos en los precios de este commodity que los países importadores. Adicionalmente, demostraron que la fluctuación en los precios del petróleo en períodos de crisis económica o las fluctuaciones que obedecen a los ciclos económicos tienen un impacto significativo en la relación entre precios del petróleo y la actividad real de las economías.

Adicionalmente, Rodríguez y Sánchez (2004) condujeron una investigación en la que analizaron los cambios en los precios del petróleo en la actividad real de la economía en los principales países industrializados. Mediante un análisis multivariado, encontraron que un incremento en los precios del petróleo tiene un efecto negativo en la actividad económica en todos los países estudiados, con excepción de Japón (en el caso de los países importadores de petróleo). Sin embargo, el efecto difiere entre los países exportadores de petróleo, puesto que el Reino Unido tuvo una afectación negativa por los altos precios mientras que Noruega tuvo una afectación positiva.

Para el caso de Ecuador, se han llevado a cabo algunos estudios empíricos para analizar el impacto de la fluctuación de los precios del petróleo en la economía. En el estudio realizado por Paladines (2017), mediante la aplicación de un modelo VAR, se concluye que un aumento en el precio del petróleo afecta positivamente el crecimiento económico del país, lo que demuestra una relación causal positiva entre el alza en el precio del petróleo y el incremento en el PIB del país.

En un estudio realizado por Rodríguez (2014) en el que se compara el desempeño de Ecuador y Colombia tomando en consideración los cambios del precio del petróleo y el desarrollo de instituciones sólidas, se encontró que si bien ambos países sufrieron la maldición de los recursos en el período de estudio (1996-2013), Ecuador se vio más afectado en virtud del poco desarrollo de sus instituciones. En este sentido, la investigación concluye que Colombia 
demostró tener un crecimiento económico más estable que el observado en la economía ecuatoriana.

Adicionalmente, en el estudio de Jin, Lim y Yoo (2016) se analizó la relación que existe entre el consumo de petróleo y el crecimiento económico (19652011), y se determinó que hay un efecto unidireccional de causalidad desde el crecimiento económico hacia el consumo de petróleo sin efectos retroactivos. Tomando en cuenta estos hallazgos, los investigadores sugieren que Ecuador puede emplear políticas de conservación sin esperar un deterioro en la economía.

\section{Metodología}

El presente estudio es de carácter exploratorio longitudinal ya que aborda el periodo comprendido desde 2008 hasta 2017, con observaciones anuales para Ecuador y Colombia. Concretamente, se escogieron doce variables de diferentes categorías con el fin de comprobar si la fluctuación de los precios del petróleo afecta o no la percepción de los ciudadanos con respecto a la situación económica de su respectivo país. La Tabla 1 contiene un resumen de las variables que se incluyen en el estudio. ${ }^{1}$

Tabla 1.

Variables empleadas en el estudio

\begin{tabular}{cclc}
\hline \multicolumn{1}{c}{ Categoría } & \multicolumn{1}{c}{ Variables } & Tipo de variable \\
\hline & - & PIB per cápita & \\
& - & Inflación & \\
1. Economía & - & PIB (Anual) & \\
& - & Porcentaje de crecimiento del PIB per cápita & \\
& - & Ingreso petrolero / IGNC & Continua \\
& - & Ingreso petrolero / PIB & \\
& - & Economic Complexity Index & \\
\hline 2. Política & - & Reformas tributarias & Categórica \\
\hline 3. Demográficas & - & Población & Continua \\
y sociales & - & Inequidad & Categóricas \\
\hline 4. Percepción & - & Latinobarómetro & \\
\hline
\end{tabular}

Elaboración propia.

En el Anexo 1 se puede encontrar información detallada de cada variable empleada en el presente estudio, incluyendo su fuente, años disponibles y categorización individual. 


\section{Contexto garcia,}

Después de establecer la validez de las variables y comprobar la independencia entre ellas, se procedió a aplicar una regresión de Poisson tomando en cuenta la naturaleza categórica de cada variable (ver sección Resultados). La relación central que se analiza en este estudio se puede establecer de la siguiente forma:

$$
\pi_{i j}=\Phi_{1}+\Phi_{2} \ldots+\Phi_{i j}+\text { error }
$$

Donde,

$\pi_{i j}$, es la percepción de los ciudadanos con respecto a la situación de la economía

$\Phi_{1}$, denota la fluctuación de los precios del petróleo

$\Phi_{i j}$, son las variables reseñadas en la Tabla 1

Para poder aplicar el modelo de regresión de Poisson, se crearon variables dummy a partir de las categorías contempladas como variable independiente. De esta forma, se evitó incurrir en multicolinearidad perfecta. Posteriormente, se procedió a analizar los resultados obtenidos.

\section{Resultados}

Inicialmente se muestran las tablas con las gráficas de la información recopilada para las variables que fueron objeto de estudio. Luego se abordan los resultados estadísticos sobre la independencia de dichas variables con la variable de control (OilPr), para terminar con los resultados de la regresión sobre la percepción ciudadana del estado de la economía en Colombia y Ecuador con respecto al precio de petróleo en el mercado internacional en las referencias BRENT y WTI.

Primero se realizó un rastreo de la información económica, social y política de ambos países. Las diferencias entre ambas naciones son evidentes, pero aun así se puede observar cierta correlación de estas variables y el precio del petróleo. Los resultados pueden verse en las gráficas 4, 5, 6, 7, 8, 9 y 10. 


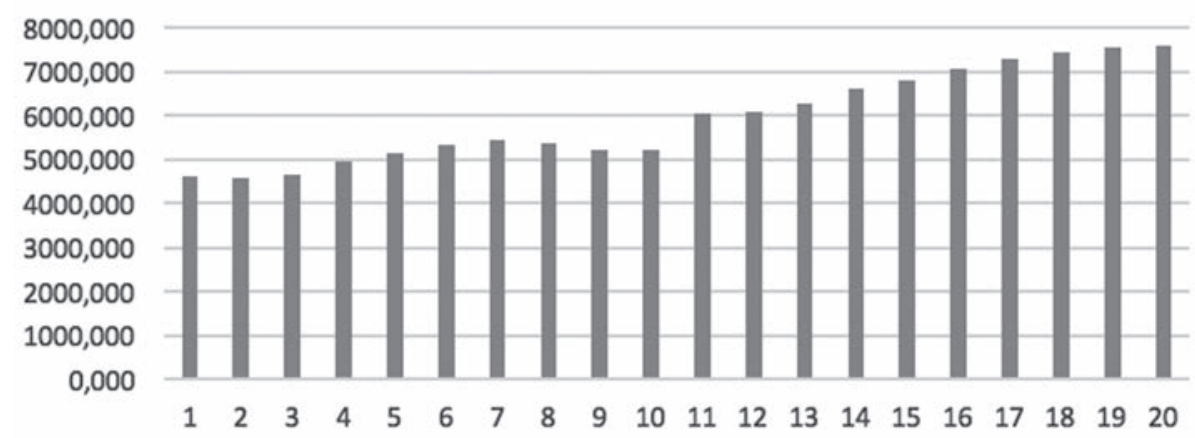

Figura 4. Variación del ingreso per cápita.

Elaboración propia con base en Banco Mundial (2018).

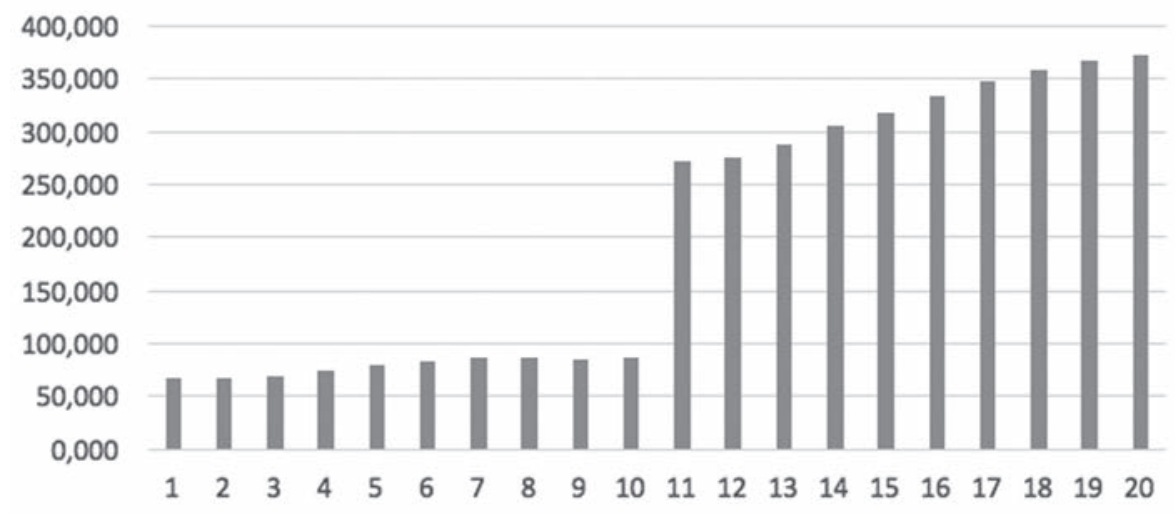

Figura 5. PIB Anual.

Elaboración propia con base en Banco Mundial (2018).

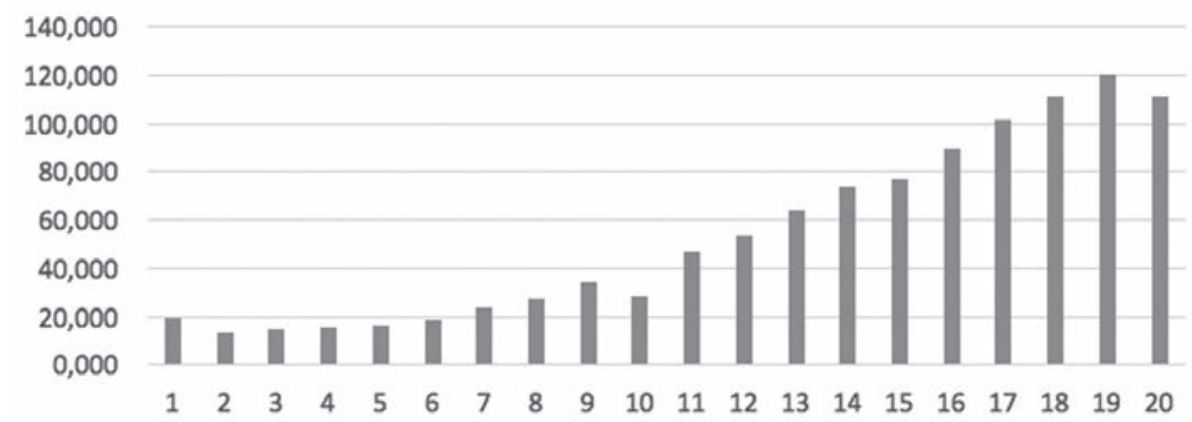

Figura 6. Valor deuda externa.

Elaboración propia con base en Banco Mundial (2018). 


\section{Contexto Garcia, c.}

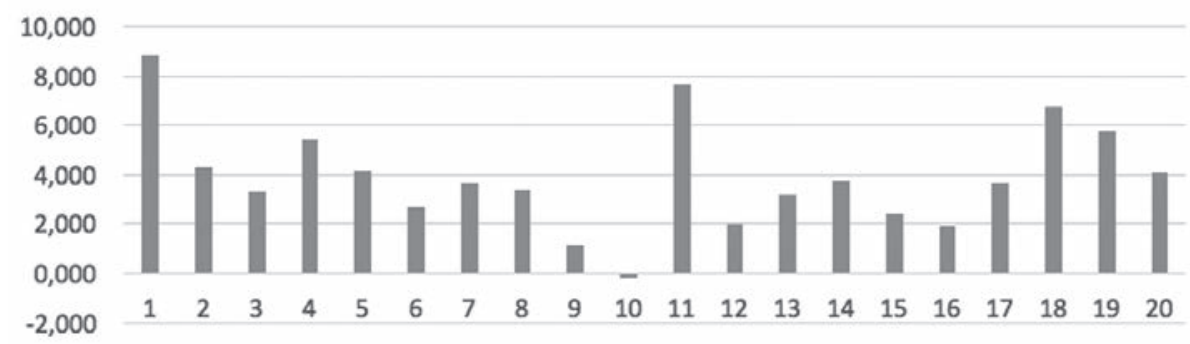

Figura 7. Inflación Anual.

Elaboración propia con base en Banco Mundial (2018).

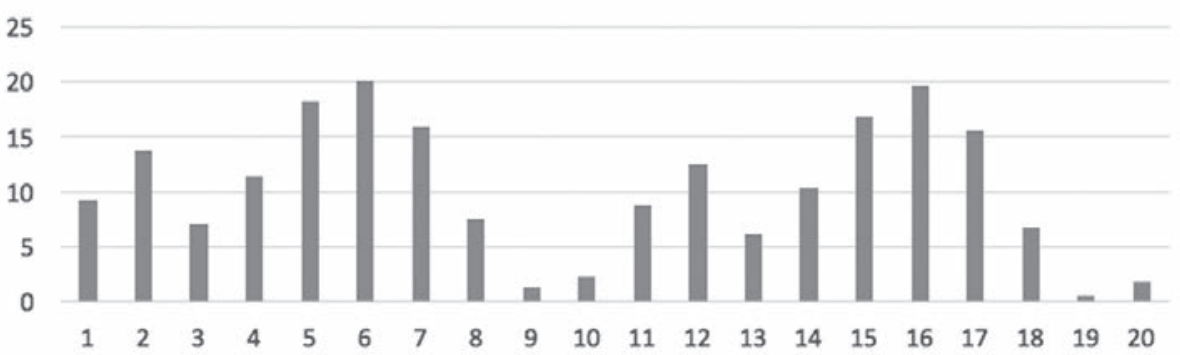

Figura 8. Porcentaje renta petrolero del total de ingresos del GNC.

Elaboración propia con base en CCG (2018) y Minhacienda (2018).

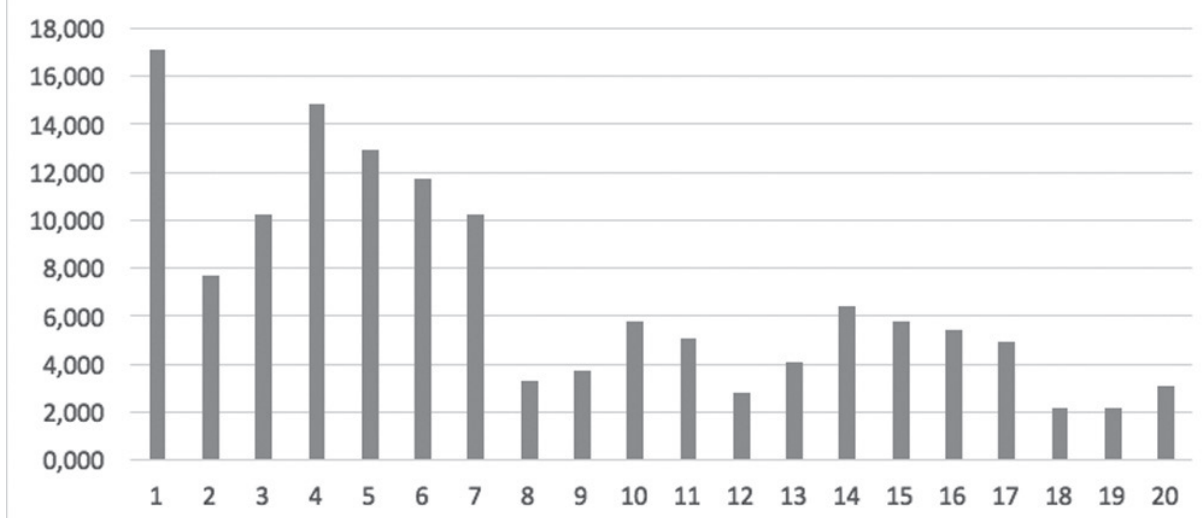

Figura 9. Ingreso petrolero como porcentaje del PIB.

Elaboración propia con base en Banco Mundial (2018). 


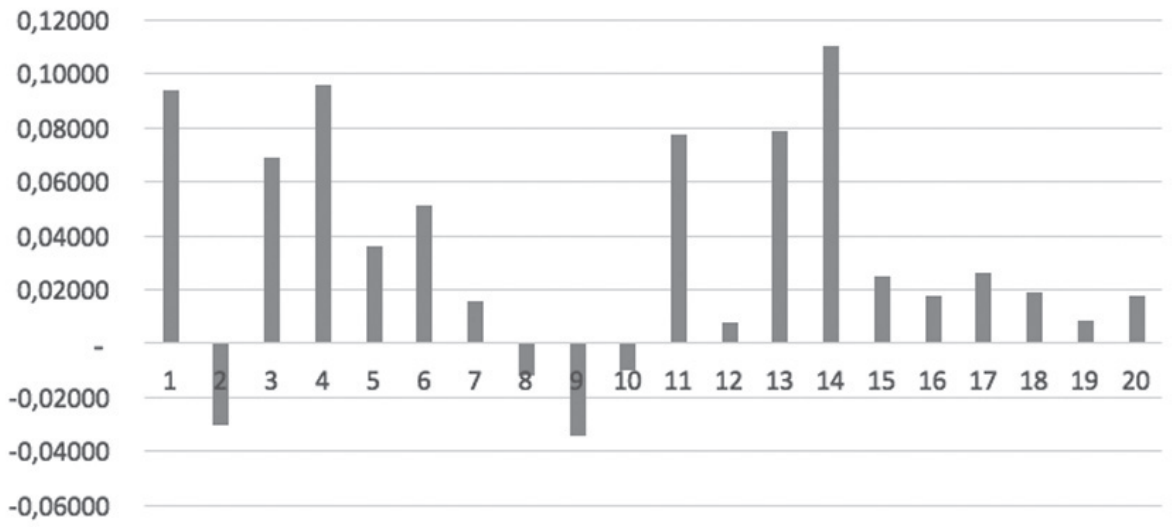

Figura 10. Aumento del PIB per cápita.

Elaboración propia con base en V-Democracy (2018).

Los datos recopilados se confrontaron con la variación del precio de barril de petróleo, tanto WTI como BRENT, con el objeto de hallar algún tipo de dependencia o relación, ya sea directa o inversamente proporcional a la variación de los precios internacionales del petróleo. Como se puede observar en la Tabla 2, la única variable que fue estadísticamente significativa como para considerarse dependiente del precio del petróleo fue la que corresponde al ingreso petrolero como porcentaje del PIB; el resto de variables mostraron independencia de este factor, dado que sus valores fueron superiores a 0,005 , lo cual nos permitió proceder con la realización de la regresión para observar si la percepción ciudadana de la economía se ve afectada positiva o negativamente con respecto a cada una de estas variables independientes (en dicha regresión se incluyó el precio del petróleo).

Es de mencionar lo particular que es el caso de la variable renta petrolera como porcentaje del ingreso del Gobierno Nacional Central, que aunque se podría suponer que sería una variable dependiente del precio del petróleo, estadísticamente no es posible afirmar tal cuestión por cuanto sus valores fueron superiores en ambos países al límite de 0,005. Esto podría deberse a que este ingreso incluye los impuestos, regalías y demás ingresos que percibe el Estado por toda la cadena de explotación y comercialización de hidrocarburos. 


\section{Contexto carciac}

\section{Análisis de la independencia}

Tabla 2.

Valores de independencia

\begin{tabular}{lcc}
\hline & Ecuador & Colombia \\
\hline Oilpr & & \\
\hline PIBpc & 0,683 & 0,273 \\
\hline PIBa & 0,301 & 0,236 \\
\hline PIBaum & 0,165 & 0,141 \\
\hline Dext & 0,04 & 0,177 \\
\hline Infl & 0,044 & 0,32 \\
\hline Pobl & 0,077 & 0,168 \\
\hline RefTrib & 0,058 & 0,766 \\
\hline IngPet & 0,016 & 0,008 \\
\hline IngPetPIB & 0 & 0 \\
\hline GINI & 0,386 & 0,186 \\
\hline ECI & 0,233 & 0,971 \\
\hline
\end{tabular}

Elaboración propia.

Entre los datos analizados, y luego de hacer los cálculos de P-value para conocer si existía o no independencia entre la variable de control (Oilpr) y las demás, se encontró que con respecto a la primera, entre los años objeto de estudio todas las variables, excepto el ingreso petrolero como porcentaje del PIB (IngPetPIB), tuvieron un comportamiento independiente de la variable de control, es decir, su comportamiento era autónomo de las fluctuaciones de Oilpr; o por lo menos estadísticamente hablando no es relevante el comportamiento de las variables con relación a la variable de control y por ende se puede desestimar una relación directa.

\section{Análisis de la regresión}

Para aplicar la regresión, se aproximó la variable dependiente (la percepción de la población sobre la economía) a una serie de preguntas aplicadas en las diferentes olas de encuestas de Latinobarómetro. En este caso, se tomó la decisión metodológica de usar la pregunta que se encontraba más directamente relacionada con el tema de interés: 
¿Considera usted que la situación económica actual del país está mucho mejor, un poco mejor, igual, un poco peor o mucho peor que hace doce meses?

En este caso, la pregunta utilizada es pertinente porque no contiene un sesgo cognitivo que condicione la respuesta del encuestado con las fluctuaciones en los precios del petróleo. De esta forma, el estudio asegura que el efecto encontrado en la regresión logra reflejar un efecto indirecto del cambio en el bienestar económico de la gente, producto del ascenso o descenso de los precios del petróleo en los mercados internacionales. Después de haber aplicado la regresión de Poisson para las variables establecidas en la sección anterior, se obtuvieron los resultados que muestra la Tabla 3.

Tabla 3.

Regresiones

\begin{tabular}{lcc}
\hline & \multicolumn{2}{c}{ Dp1st } \\
\hline Oilpr & Ecuador & Colombia \\
\hline Pibpc & 0,835 & 0,944 \\
\hline Piba & 0,14 & 0,329 \\
\hline Pibaum & 0,152 & 0,331 \\
\hline Dext & 0,768 & 0,934000 \\
\hline Infl & 0,353 & 0,322 \\
\hline Pobl & 0,368 & 0,79 \\
\hline Reftrib & 0,179 & 0,333 \\
\hline Ingpet & 0,574 & 1,0000000 \\
\hline Gini & 0,898 & 0,93 \\
\hline ECI & 0,152 & 0,513 \\
\hline & 0,373 & 0,351000 \\
\hline
\end{tabular}

Elaboración propia.

Tanto en Colombia como en Ecuador las variables estudiadas en la regresión no arrojaron resultados estadísticamente significativos puesto que sus valores-p son mayores que 0.05 . La interpretación de estos datos demuestra que la percepción de la ciudadanía no viene condicionada por el comportamiento en la economía. Las razones se pueden explicar por la desconexión que tienen los ciudadanos con respecto a los fenómenos económicos específicos. Por ejemplo, una persona se verá afectada por la crisis en los precios del petróleo si experimentase un efecto inmediato (i. e. cambios en los precios en la canasta básica de alimentos). 


\section{Contexto Garcia, c.}

\section{Conclusiones}

El objetivo general que dio luz a este trabajo era analizar la relación que existe entre la fluctuación de los precios del petróleo y varios indicadores de percepción económica en Colombia y Ecuador (2008-2017), frente a lo cual se puede concluir lo siguiente:

Con respecto a si los precios del petróleo guardan relación con la percepción económica en Colombia o Ecuador, no hay evidencia que pueda ser usada, al menos estadísticamente, para sostener dicha idea. Por esta razón nuestra hipótesis, que la ciudadanía puede percibir una mejor o peor situación económica al presentarse un alza o una baja en la cotización del barril de petróleo, se puede descartar.

Uno de los principales hallazgos, además de haber encontrado una independencia entre la percepción económica y el precio del barril de crudo, es que, aparentemente, desde el modelo estadístico aplicado en nuestro estudio, no hay una interacción proporcional en el comportamiento del precio del petróleo y su incidencia en la producción nacional (Producto Interno Bruto).

Fue posible hallar la percepción económica de los ciudadanos en todos los años objeto de estudios gracias a información secundaria tomada de las encuestas de Latinobarómetro, con lo que pudimos dar respuesta a nuestro primer objetivo específico. Por otro lado, al encontrar que la población no percibe cambios en su diario vivir, o al menos no cuando los precios del petróleo son adversos o favorables, entre los años estudiados, no es factible establecer una correlación entre el bienestar económico que los mismos ciudadanos ecuatorianos o colombianos puedan sentir y la forma en que el precio del petróleo afecta, principalmente, las finanzas públicas, la balanza comercial y por consiguiente la economía nacional.

Una de las principales limitaciones del estudio fue la dificultad de conseguir artículos que abordaran el precio del petróleo no tanto desde una perspectiva netamente económica o de cómo afecta la política fiscal de un Estado, sino desde la percepción ciudadana y la relación que pueda haber entre lo que los ciudadanos sienten y lo que sería la realidad económica de sus países.

En cuanto a posibles líneas de investigación, se deja abierto el espacio para analizar el comportamiento del precio del petróleo y su relación con el PIB de Colombia y Ecuador, pero desde otro modelo estadístico, matemático o econométrico. 


\section{Referencias}

Banco Central del Ecuador. (2018). Micrositio de información económica.

Recuperadodehttps://www.bce.fin.ec/index.php/informacioneconomica/

Banco Mundial. (2018). Rentas del petróleo (\% Del PIB) 2008-2016. Recuperado de https://datos.bancomundial.org/

Cámara de Comercio de Guayaquil. (CCG) (2018). Estadísticas de Comercio Exterior. Recuperado de http://www.lacamara.org/website/estadisticasde-comercio-exterior/

Clegg, J. (2016). Perception vs Reality: How does the British electorate evaluate economic performance of incumbent governments in the post war period? Discussion Papers in Economic and Social History, 143, 1-66. Recuperado de https://www.economics.ox.ac.uk/materials/ papers/14424/143marchclegg-3.pdf

Comisión Económica para América Latina y el Caribe (CEPAL). (2013). Natural resources: Status and trends towards a regional development agenda in Latin America and the Caribbean. Recuperado de https:// repositorio.cepal.org/bitstream/handle/11362/35892/S2013808_ en.pdf? sequence $=1 \&$ isAllowed $=\mathrm{y}$

Corporación Latinobarómetro. (2018). Recuperado de http://www. latinobarometro.org/lat.jsp

Cuñado, J. y Pérez de Gracia, F. (2003). Do oil price shocks matter? Evidence from some European countries. Energy Economics, 25(2), 137-154.

De Miguel P., C., Manzano, B. y Martín, J. (2012). Mercado del petróleo y actividad económica. Un estado de la cuestión. Economía industrial, 384, 99-106.

DeSilver, D. (2017). People's views of their national economies don't always square with data. FactTank. News in the numbers. Pew Research Centre. Recuperado de http://www.pewresearch.org/fact$\operatorname{tank} / 2017 / 06 / 27 /$ peoples-views-of-their-national-economies-dontalways-square-with-data/

Graham, C. \& S. Pettinato (2002). Frustrated achievers: Winners, losers and subjectivewell-beinginnewmarketeconomies. TheJournalofDevelopment Studies, 38(4), 100-140, doi: 10.1080/00220380412331322431 


\section{Contexto Garcia, c.}

Jiménez, R. \& Sánchez, M. (2004). Oil Price Shocks and Real GDP Growth: Empirical Evidence for Some OECD Countries. ECB Working Paper No. 362.

Jin, S., Lim, S. \& Seung-Hoon Y. (2016). Causal relationship between oil consumption and economic growth in Ecuador, Energy Sources, Part B. Economics, Planning, and Policy, 11(9), 782-787. doi: $10.1080 / 15567249.2013 .790520$

Karl, T. (1997). The Paradox of Plenty. Oil Booms and Petro-States. Berkeley: University of California Press.

Kramer, G. (1971). Short-term fluctuations in U. S. voting behavior, 18961964. American Political Science Review, 65(1), 131-143.

Lewis-Beck, M. \& Stegmaier, M. (2007). Economic models of voting. In R. J. Dalton \& H.-D. Klingemann (Eds.), The Oxford Handbook of Political Behavior (pp. 518-537). Oxford: Oxford University Press.

Lewis-Beck, M. \& Stegmaier, M. (2009). American voter to economic voter: Evolution of an idea. Electoral Studies, 28(4), 625-631.

Lewis-Beck, M., Martini, N. \& Kiewiet, D. (2013). The nature of economic perceptions in mass publics. Electoral Studies, 32(3), 524-528. Recuperado de http://www.sciencedirect.com/science/article/pii/ S0261379413000747

Limin, D., He, Y. \& Chu, W. (2010). The relationship between oil price shocks and China's macro-economy: An empirical analysis. Energy Policy 38(8), 4142-4151.

Ministerio de Hacienda y Crédito Público (Minhacienda). (2018). Dinamismo del petróleo en la economía colombiana. Colombia Repunta. Recuperado de http://www.andi.com.co/Uploads/MauricioCardenas.pdf

Paladines, J. \& Paladines, A. (2017). Consequences of oil and food price shocks on the Ecuadorian economy. International Journal of Energy Economics and Policy, 7(3), 146-151.

Rodríguez, O. (2014). Oil policies and the resource curse in Colombia and Ecuador. Papel Político, 19(2), 459-496. Recuperado de http://dx.doi. org/10.11144/Javeriana.PAPO19-2.oprc 
Santillán, R. \& Venegas, F. (2015). Impact of oil prices on economic growth in Latin American oil exporting countries (1990-2014): A panel data analysis. Social Science Research Network, 1-30. http://dx.doi.org/10.2139/ ssrn.2692024. Recuperado de https://ssrn.com/abstract=2692024.

Sehgal, N. \& Pandey, K. (2015). Aftermath of 2008 financial crisis on oil prices. In Proceedings of 7th International Joint Conference on Knowledge Discovery, Knowledge Engineering and Knowledge Management. Vol. 1 (pp. 235-240). Recuperado de http://www.scitepress.org/ Papers/2015/55969/55969.pdf

Thaler, R. y Sunstein, C. (2008). Un pequeño empujón: El impulso que necesitas para tomar mejores decisiones sobre salud, dinero y felicidad. España: Taurus.

V-Democracy. (2018). Varieties of Democracy: V-8. Recuperado de https:// www.v-dem.net/en/data/data-version-8/

\section{Para citar este artículo:}

García, C. (2019). La variación de los precios del petróleo y su influencia en las economías de Colombia y Ecuador. Análisis comparativo de indicadores macroeconómicos y sociodemográficos entre 2008 y 2017. En-Contexto, 7(11), 185-207. 


\section{Contexto Garcia, c.}

\section{Anexos}

\section{Anexo 1}

A. Indicadores recopilados para Ecuador y Colombia (2007-2017)

\begin{tabular}{|c|c|c|c|c|c|c|c|c|c|c|}
\hline Code & Pais & Year & Oilpr & PIBpc & PIBa & PIBaum & Dext & Infl & Pobl & RefTrib \\
\hline & 1 Ecuador & 2008 & 99,670 & 4624,197 & 66,808 & 0,09424 & 19,050 & 8,830 & 14447562,000 & 1,000 \\
\hline & 1 Ecuador & 2009 & 61,950 & 4573,247 & 67,187 . & 0,03026 & 13,351 & 4,310 & 14691275,000 & 1,000 \\
\hline & 1 Ecuador & 2010 & 79,480 & 4657,302 & 69,555 & 0,06886 & 15,046 & 3,330 & 14934690,000 & 1,000 \\
\hline & 1 Ecuador & 2011 & 94,880 & 4943,423 & 75,028 & 0,09593 & 15,899 & 5,410 & 15177375,000 & 1,000 \\
\hline & 1 Ecuador & 2012 & 94,050 & 5140,263 & 79,261 & 0,03575 & 16,400 & 4,160 & 15419666,000 & 1,000 \\
\hline & 1 Ecuador & 2013 & 97,980 & 5311,212 & 83,182 & 0,05154 & 18,619 & 2,700 & 15661547,000 & 1,000 \\
\hline & 1 Ecuador & 2014 & 93,170 & 5428,714 & 86,333 & 0,01572 & 24,158 & 3,670 & 15903112,000 & 1,000 \\
\hline & 1 Ecuador & 2015 & 48,660 & 5352,876 & 86,419 . & 0,01195 & 27,257 & 3,380 & 16144368,000 & 0,000 \\
\hline & 1 Ecuador & 2016 & 43,290 & 5191,100 & 85,057 ; & 0,03463 & 34,083 & 1,120 & 16385068,000 & 1,000 \\
\hline & 1 Ecuador & 2017 & 50,800 & 5209,618 & 87,607 . & 0,01029 & 28,500 & $\cdot 0,200$ & 16624858,000 & 0,000 \\
\hline & 2 Colombia & 2008 & 96,940 & 6048,095 & 271,569 & 0,07770 & 46,688 & 7,670 & 44451147,000 & 0,000 \\
\hline & 2 Colombia & 2009 & 61,740 & 6078,315 & 276,054 & 0,00809 & 53,331 & 2,000 & 44978832,000 & 1,000 \\
\hline & 2 Colombia & 2010 & 79,610 & 6250,655 & 287,018 & 0,07874 & 64,097 & 3,170 & 45509584,000 & 1,000 \\
\hline & 2 Colombia & 2011 & 111,260 & 6592,402 & 305,931 & 0,11019 & 73,813 & 3,730 & 46044601,000 & 0,000 \\
\hline & 2 Colombia & 2012 & 111,630 & 6789,526 & 318,303 & 0,02460 & 76,782 & 2,440 & 46581823,000 & 1,000 \\
\hline & 2 Colombia & 2013 & 108,560 & 7051,040 & 333,817 & 0,01780 & 89,720 & 1,940 & 47121089,000 & 0,000 \\
\hline & 2 Colombia & 2014 & 98,970 & 7291,692 & 348,484 & 0,02652 & 101,376 & 3,660 & 47661787,000 & 1,000 \\
\hline & 2 Colombia & 2015 & 52,320 & 7446,182 & 359,120 & 0,01894 & 110,875 & 6,770 & 48203405,000 & 0,000 \\
\hline & 2 Colombia & 2016 & 43,640 & 7531,983 & 366,457 . & 0,00817 & 120,282 & 5,750 & 48747708,000 & 1,000 \\
\hline & 2 Colombia & 2017 & 54,130 & 7600,759 & 372,936 & 0,01787 & 110,844 & 4,090 & 49291609,000 & 0,000 \\
\hline
\end{tabular}

\begin{tabular}{|c|c|c|c|c|c|c|c|c|c|c|c|c|c|}
\hline Code & Pais & Year & Ingpet & IngPetPIB & GINI & ECI & P1st & P2ST & PASTGbSC & PSSTGBS & P6SnICC1 & P7sticc1 & \\
\hline & 1 Ecuador & 2008 & 9,2 & 17,135 & 49,150 & $-0,803638$ & 1 & 1 & & 1 & 2 & 3 & 3 \\
\hline & 1 Ecuador & 2009 & 13,7 & 7,675 & 48,700 & $-0,867623$ & 1 & 1 & & 2 & 2 & 3 & 3 \\
\hline & 1 Ecuador & 2010 & 7,1 & 10,251 & 48,700 & $-0,7082$ & 1 & 1 & & 2 & 2 & 3 & 3 \\
\hline & 1 Ecuador & 2011 & 11,4 & 14,871 & 45,850 & $-0,770023$ & 2 & 2 & & 2 & 2 & 3 & 3 \\
\hline & 1 Ecuador & 2012 & 18,2 & 12,967 & 46,200 & $-0,708563$ & 2 & 2 & & 2 & 2 & 3 & 4 \\
\hline & 1 Ecuador & 2013 & 20,1 & 11,697 & 46,950 & $-1,06674$ & 2 & 2 & & 4 & 2 & 4 & 4 \\
\hline & 1 Ecuador & 2014 & 15,9 & 10,265 & 45,200 & $-1,30875$ & 3 & 2 & & 4 & 3 & 4 & 4 \\
\hline & 1 Ecuador & 2015 & 7,6 & 3,310 & 45,200 & $-1,33499$ & 4 & 3 & & 4 & 3 & 4 & 5 \\
\hline & 1 Ecuador & 2016 & 1,3 . & 3,762 & 45,200 & $-0,989348$ & 4 & 3 & & 4 & 4 & 5 & 5 \\
\hline & 1 Ecuador & 2017 & $2,3^{\prime}$ & 5,779 & 45,200 & $-1,21102933$ & 4 & 3 & & s & 4 & $s$ & 5 \\
\hline & 2 Colombia & 2008 & 8,800 & 5,055 & 54,000 & 0,220323 & 1 & 1 & & 1 & 2 & 3 & 3 \\
\hline & 2 Colombia & 2009 & 12,500 & 2,822 & 53,600 & 0,21155 & 1 & 1 & & 1 & 2 & 3 & 3 \\
\hline & 2 Colombia & 2010 & 6,200 & 4,052 & 53,650 & 0,18691 & 2 & 2 & & 2 & 2 & 3 & 3 \\
\hline & 2 Colombia & 2011 & 10,300 & 6,426 & 53,100 & $-0,001219$ & 2 & 2 & & 2 & 2 & 3 & 4 \\
\hline & 2 Colombia & 2012 & 16,900 & 5,763 & 52,300 & 0,049744 & 2 & 2 & & 3 & 3 & 4 & 4 \\
\hline & 2 Colombia & 2013 & 19,600 & 5,442 & 51,300 & $-0,234596$ & 2 & 2 & & 4 & 3 & 4 & 4 \\
\hline & 2 Colombia & 2014 & 15,600 & 4,966 & 53,300 & $-0,194463$ & 3 & 3 & & 4 & 3 & 4 & 4 \\
\hline & 2 Colombia & 2015 & 6,800 & 2,184 & 53,300 & $-0,216272$ & 4 & 3 & & 4 & 3 & 5 & 4 \\
\hline & 2 Colombia & 2016 & 0,600 & 2,180 & 53,300 & 0,00253314 & 4 & 3 & & 5 & 5 & 5 & 5 \\
\hline & 2 Colombia & 2017 & $1,800^{\prime}$ & 3,110 & $\$ 3,300$ & 0,13606729 & 4 & 3 & & s & 5 & 5 & s \\
\hline
\end{tabular}

B. Aplicación de desviación estándar

\begin{tabular}{|l|r|r|l|r|r|}
\hline \multicolumn{3}{|c|}{ Ecuador } & \multicolumn{3}{c|}{ Colombia } \\
\hline Estadística & Media & Desv. Estand. & Estadística & Media & Desv. Estand. \\
\hline Oilpr & 76,393 & 7,2118 & Oilpr & 81,88 & 8,4957 \\
\hline PIBpc & 5043,195 & 101,6876 & PIBpc & 6868,065 & 191,0264 \\
\hline PIBa & 78643,7 & $2.643,7480$ & PIBa & 323968,9 & 11972,66 \\
\hline PIBaum & 0,07104 & 0,0342 & PIBaum & 0,038862 & 0,0114077 \\
\hline Dext & 21236,3 & 2177,1250 & Dext & 84780,8 & 8146,283 \\
\hline InfI & 3,67100 & 0,7668 & Infl & 4,1220 & 0,6290925 \\
\hline Pobl & 1550000 & $231.638,2000$ & Pobl & 46900000 & 515311,9 \\
\hline IngPet & 10,68 & 2,013499 & IngPet & 9,91 & 1,997523 \\
\hline IngPetPIB & 9,7712 & 1,4637 & IngPetPIB & 4,2 & 0,4888982 \\
\hline GINI & 46,56 & 0,5167 & GINI & 53,115 & 0,2449546 \\
\hline ECI & $-0,9768904$ & 0,0767651 & ECI & $-0,0111557$ & 0,05653 \\
\hline
\end{tabular}


C. P-Value tras aplicación de desviación estándar

\begin{tabular}{|l|r|l|r|}
\hline \multicolumn{2}{|c|}{ Ecuador } & \multicolumn{2}{c|}{ Colombia } \\
\hline Estadística & $\boldsymbol{P}$. Value & Estadística & P. Value \\
\hline Oilpr & & Oilpr & \\
\hline PIBpc & 0,683 & PIBpc & 0,273 \\
\hline PIBa & 0,301 & PIBa & 0,236 \\
\hline PIBaum & 0,165 & PIBaum & 0,141 \\
\hline Dext & 0,04 & Dext & 0,177 \\
\hline Infl & 0,044 & Infl & 0,32 \\
\hline Pobl & 0,077 & Pobl & 0,168 \\
\hline RefTrib & 0,058 & RefTrib & 0,766 \\
\hline IngPet & 0,016 & IngPet & 0,008 \\
\hline IngPetPIB & 0 & IngPetPIB & 0 \\
\hline GINI & 0,386 & GINI & 0,186 \\
\hline ECI & 0,233 & ECI & 0,971 \\
\hline
\end{tabular}

D. Aplicación de Regresión de Poisson

\begin{tabular}{|c|c|c|c|c|c|c|}
\hline \multicolumn{7}{|c|}{ Ecuador Standard Error } \\
\hline & dp1st & dp2st & dp4stgbs & dp5stgbs & dp6sticc1 & dp7sticc1 \\
\hline Oilpr & \begin{tabular}{|l|}
0,0172618 \\
\end{tabular} & 0,172618 & 0,0151621 & 0,0146163 & 0,0146163 & 0,0146163 \\
\hline Pibpc & 0,001755 & 0,001755 & 0,001141 & 0,0010366 & 0,0010366 & 0,0010366 \\
\hline Piba & 0,0000669 & 0,0000669 & 0,000044 & 0,0000399 & 0,0000399 & 0,0000399 \\
\hline Pibaum & 3,334082 & 3,334082 & 3,332264 & 3,079739 & 3,079739 & 3,079739 \\
\hline Dext & 0,0000543 & 0,0000543 & 0,0000505 & 0,0000484 & 0,0000484 & 0,0000484 \\
\hline $\operatorname{Infl}$ & 0,1798756 & 0,1798756 & 0,1550789 & 0,1374606 & 0,1374606 & 0,1374606 \\
\hline Pobl & 0,000000596 & 0,000000596 & 0,000000484 & 0,000000455 & 0,000000455 & $4,55 \mathrm{E}-07$ \\
\hline Reftrib & 0,83666 & 0,83666 & 0,8017837 & 0,7905694 & 0,7905694 & 0,7905694 \\
\hline Ingpet & 0,0626549 & 0,0626549 & 0,0552155 & 0,0523513 & 0,0523513 & 0,0523513 \\
\hline Gini & 0,4964505 & 0,4964505 & 0,2348574 & 0,2040009 & 0,2040009 & 0,2040009 \\
\hline $\mathrm{ECl}$ & 1,619187 & 1,619187 & 1,43079 & 1,37314 & 1,37314 & 1,37314 \\
\hline \multicolumn{7}{|c|}{ Ecuador $\mathrm{P}>(\mathrm{Z})$} \\
\hline & dp1st & dp2st & dp4stgbs & dp5stgbs & dp6sticc1 & dp7sticc1 \\
\hline Oilpr & 0,835 & 0,835 & 0,72 & 1,00000 & 1,00000 & 1,00000 \\
\hline Pibpc & 0,14 & 0,14 & 0,648 & 1,00000 & 1,00000 & 1,00000 \\
\hline Piba & 0,152 & 0,152 & 0,62 & 1,00000 & 1,00000 & 1,00000 \\
\hline Pibaum & 0,768 & 0,768 & 0,94 & 1,00000 & 1,00000 & 1,00000 \\
\hline Dext & 0,353 & 0,353 & 0,911 & 1,00000 & 1,00000 & 1,00000 \\
\hline $\operatorname{Infl}$ & 0,368 & 0,368 & 0,454 & 1,00000 & 1,00000 & 1,00000 \\
\hline Pobl & 0,179 & 0,179 & 0,602 & 1,00000 & 1,00000 & 1,00000 \\
\hline Reftrib & 0,574 & 0,574 & 0,868 & 1,00000 & 1,00000 & 1,00000 \\
\hline Ingpet & 0,898 & 0,898 & 0,935 & 1,00000 & 1,00000 & 1,00000 \\
\hline Gini & 0,152 & 0,152 & 0,58 & 1,00000 & 1,00000 & 1,00000 \\
\hline $\mathrm{ECl}$ & 0,373 & 0,373 & 0,802 & 1,00000 & 1,00000 & 1,00000 \\
\hline
\end{tabular}




\section{Contexto Garcia, c.}

\begin{tabular}{|c|c|c|c|c|c|c|}
\hline \multicolumn{7}{|c|}{ Colombia Standard Error } \\
\hline & dp1st & dp2st & dp4stgbs & dp5stgbs & dp6sticc1 & dp7sticc1 \\
\hline Oilpr & \begin{tabular}{|r|}
0,0139092 \\
\end{tabular} & \begin{tabular}{|r|}
0,0139092 \\
\end{tabular} & 0,0139092 & 0,0124074 & 0,0124074 & 0,0124074 \\
\hline Pibpc & 0,0006715 & 0,0006715 & 0,0006715 & 0,0005518 & 0,0005518 & 0,0005518 \\
\hline Piba & 0,0000106 & 0,0000106 & 0,0000106 & 0,0000088 & 0,0000088 & 0,0000088 \\
\hline Pibaum & 10,488060 & 10,488060 & 10,488060 & 9,240214 & 9,240214 & 9,240214 \\
\hline Dext & 0,0000154 & 0,0000154 & 0,0000154 & 0,0000129 & 0,0000129 & 0,0000129 \\
\hline Infl & 0,1936734 & 0,1936734 & 0,1936734 & 0,1675577 & 0,1675577 & 0,1675577 \\
\hline Pobl & 0,00000023 & 0,00000023 & 0,00000023 & 0,00000025 & 0,00000025 & 0,00000025 \\
\hline Reftrib & 0,7071068 & 0,7071068 & 0,7071068 & 0,6324555 & 0,6324555 & 0,6324555 \\
\hline Ingpet & 0,059027 & 0,059027 & 0,059027 & 0,05277 & 0,05277 & 0,05277 \\
\hline Gini & 0,4223334 & 0,4223334 & 0,4223334 & 0,4303215 & 0,4303215 & 0,4303215 \\
\hline $\mathrm{ECl}$ & 2,206459 & 2,206459 & 2,206459 & 1,86466 & 1,86466 & 1,86466 \\
\hline \multicolumn{7}{|c|}{ Colombia $\mathrm{P}>(\mathrm{z})$} \\
\hline & dp1st & dp2st & dp4stgbs & dp5stgbs & dp6sticc1 & dp7sticc1 \\
\hline Oilpr & \begin{tabular}{|r|}
0,944 \\
\end{tabular} & \begin{tabular}{r|}
0,944 \\
\end{tabular} & \begin{tabular}{|r|}
0,944 \\
\end{tabular} & 1,0000000 & 1,0000000 & 1,0000000 \\
\hline Pibpc & 0,329 & 0,329 & 0,329 & 1,0000000 & 1,0000000 & 1,0000000 \\
\hline Piba & 0,331 & 0,331 & 0,331 & 1,0000000 & 1,0000000 & 1,0000000 \\
\hline Pibaum & 0,934000 & 0,934000 & 0,934000 & 1,0000000 & 1,0000000 & 1,0000000 \\
\hline Dext & 0,322 & 0,322 & 0,322 & 1,0000000 & 1,0000000 & 1,0000000 \\
\hline Infl & 0,79 & 0,79 & 0,79 & 1,0000000 & 1,0000000 & 1,0000000 \\
\hline Pobl & 0,333 & 0,333 & 0,333 & 1,0000000 & 1,0000000 & 1,0000000 \\
\hline Reftrib & 1,0000000 & 1,0000000 & 1,0000000 & 1,0000000 & 1,0000000 & 1,0000000 \\
\hline Ingpet & 0,93 & 0,93 & 0,93 & 1,0000000 & 1,0000000 & 1,0000000 \\
\hline Gini & 0,513 & 0,513 & 0,513 & 1,0000000 & 1,0000000 & 1,0000000 \\
\hline $\mathrm{ECl}$ & 0,351000 & 0,351000 & 0,351000 & 1,0000000 & 1,0000000 & 1,0000000 \\
\hline
\end{tabular}

\section{E. Preguntas Latinobarómetro}

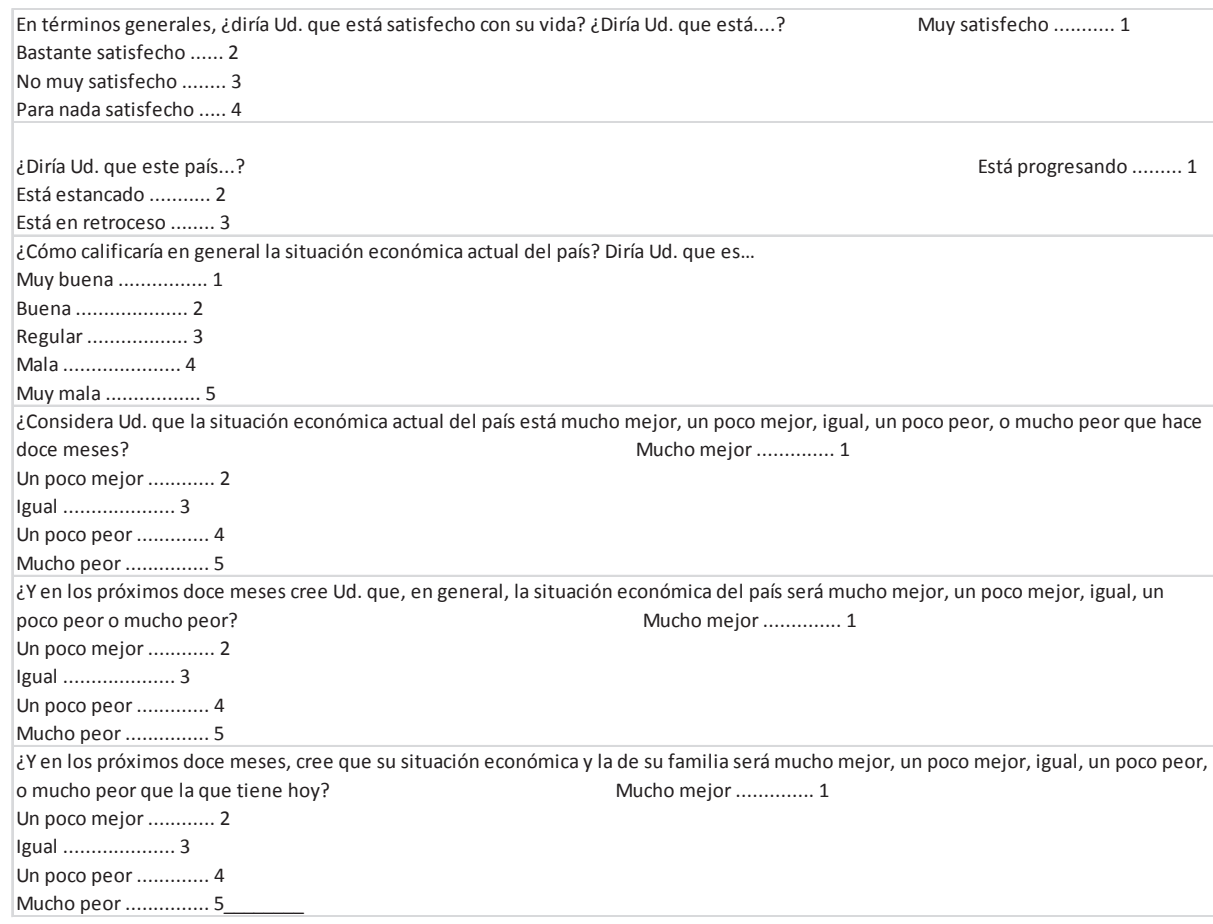

